Original Research Article

\title{
A comparative study on safety and efficacy of tolperisone with etodolac and thiocolchicoside with etodolac in patients of acute low back pain with musculoskeletal spasm
}

\author{
Tanu Garg*, Vijay K. Yadav
}

\begin{abstract}
Department of Pharmacology, Peoples College of Medical Sciences and Research Centre, Bhopal, Madhya Pradesh, India
\end{abstract}

Received: 28 August 2019

Revised: 21 September 2019

Accepted: 27 September 2019

*Correspondence to:

Dr. Tanu Garg,

Email: tanu43210@gmail.com

Copyright: (C) the author(s), publisher and licensee Medip Academy. This is an openaccess article distributed under the terms of the Creative Commons Attribution NonCommercial License, which permits unrestricted noncommercial use, distribution, and reproduction in any medium, provided the original work is properly cited.

\begin{abstract}
Background: Low back pain is one of the most common health problems in society which leads to considerable disability, loss of work days, and puts a huge burden on socioeconomic and healthcare system. It is often associated with musculoskeletal spasm. The aim of the study was to compare the efficacy and safety of tolperisone and thiocolchicoside in combination with etodolac in patients of acute low back pain associated with musculoskeletal spasm.

Methods: it was a prospective, randomized, open label study which included patients of either sex between age 18-50 years of acute low back pain with musculoskeletal spasm. Patients were allocated in two groups. Patients in 'Group A' were given tolperisone $150 \mathrm{mg}+$ etodolac $400 \mathrm{mg}$ twice a day and patients in 'Group B' were given thiocolchicoside $4 \mathrm{mg}$ + etodolac $400 \mathrm{mg}$ twice a day. Efficacy of two drugs was assessed by decrease in finger to floor distance (FFD), decrease in pain as per visual analog scale (VAS) and global assessment of efficacy of treatment by physician. Follow-up of the patients was done on day 3 and 7 of treatment. Various side effects reported by patients in both the groups were also recorded and compared.

Results: Both tolperisone and thiocolchicoside caused significant decrease in FFD, reduced pain score thus indicating decrease in pain and spasm. Side effects reported in both groups were mild and did not result in discontinuation of therapy.

Conclusions: Tolperisone was found to have efficacy similar to that of thiocolchicoside though number of side effects reported was more with tolperisone.
\end{abstract}

Keywords: Thiocolchicoside, Tolperisone, Acute low back pain, Musculoskeletal spasm

\section{INTRODUCTION}

Low back pain is one of the most common health problems in society and causes considerable disability, work absenteeism, and use of health services. ${ }^{1}$ Almost 85 $90 \%$ of adults younger than 50 years suffer from at least one episode of LBP in their life time and $15-30 \%$ at any given time. $^{1}$

Most common cause of LBP is mechanical (80-90\% cases), out of which $65-70 \%$ cases of LBP are attributed to lumbar strain and sprain. ${ }^{2}$
Mechanical LBP exists in every culture and society although more prevalent in countries with higher per capita income. ${ }^{3}$ The prevalence of LBP is rapidly increasing in developing countries due to adaptation of the lifestyle of western civilization.

Mechanical LBP is the most common cause of workrelated disability in persons younger than 45 years and the third most common cause of disability in individuals older than 45 years. ${ }^{3}$

LBP is often associated with acute musculoskeletal spasm. Spasm is an involuntary painful contraction of 
muscle that interferes with the function and causes muscular disorders.

Management of acute musculoskeletal spasm with LBP is a multimodal approach. It includes pharmacological therapy as well as conservative (non-pharmacological) therapy. ${ }^{2}$

Pharmacological therapy includes non-steroidal antiinflammatory drugs (NSAIDs) or muscle relaxants or both. The main limitation of using centrally acting muscle relaxants in the treatment of acute LBP is sedation as it affects daily activity and decreases working capability. Tolperisone and thiocolchicoside are centrally acting muscle relaxants with a lesser degree of sedation and good efficacy in acute musculoskeletal conditions.

Till date, very few studies have been done on centrally acting muscle relaxants. There is only one multicentre trial in which tolperisone and thiocolchicoside have been directly compared.

This study was done keeping in mind that LBP puts a huge burden on socioeconomic and healthcare system, thus it will help decide the use of centrally acting muscle relaxants in patients of acute LBP with musculoskeletal spasm.

\section{METHODS}

It was a prospective, randomized, open label study. The study was started after taking all necessary approvals.

\section{Study period}

Study was carried out from November 2012-April 2014.

The study included patients of either sex between 18-50 years of age and presented with acute low back pain with musculoskeletal spasm to the Outpatient Department of Orthopaedics, People's College of Medical Sciences and Research Centre, Bhanpur, Bhopal.

\section{Exclusion criteria}

Exclusion criteria were patients with acute muscle spasms who needed parenteral therapy, surgery or hospital admissions for management; patients with spinal deformities like scoliosis, kyphosis, lordosis, fixed pelvic obliquity; patients with hyperlaxity of joints; patients with acute muscle spasms due to causes other than those mentioned in inclusion criteria; any primary hip disorder or sacroiliac joint pathology; hamstring spasm; pregnant or lactating women; patients with severe cardiac, hepatic, renal, pulmonary disease or uncontrolled diabetes mellitus; patients with peptic ulcer and GERD; patients with known hypersensitivity reaction to any of the drugs in study; patients unwilling or unable to comply with the study procedures.
Patients selected for the study were then allocated into two groups based on simple random sampling. Patients in 'Group A' were given combination of tolperisone $150 \mathrm{mg}$ and etodolac $400 \mathrm{mg}$ twice a day and patients in 'Group B' were given the combination of thiocolchicoside $4 \mathrm{mg}$ and etodolac $400 \mathrm{mg}$ twice a day.

Drugs were given orally for seven days to all the patients who presented with acute low back pain with muscle spasm irrespective of degree of spasm.

\section{Efficacy parameters}

Patients were assessed by comparing the various parameters at baseline i.e. before starting the therapy and then on follow up visits on day 3 and day 7 for relief of pain and spasm and for any adverse drug reaction.

\section{Finger to floor distance}

Patients were asked to bend forward as far as possible without flexing the knees and attempt to touch the floor with fingertips. He/she was asked to go only as far as he/she can bend. The distance (in $\mathrm{cm}$ ) between the patient's middle finger and the floor was measured.

The decrease in Finger to floor distance (FFD) on follow up visits was indicative of decrease in muscle spasm.

\section{Visual analogue scale}

All patients selected for the study were asked to point the severity of pain on $10 \mathrm{~cm}$ visual analogue scale where 0 indicated no pain while 10 indicated unbearable pain. This score was used as a baseline assessment of pain with follow-up measures indicating whether pain is reducing or not. The change in pain scores over time was measured by the difference between the baseline visual analogue scale (VAS) and the VAS at each follow-up measurement, positive values indicated decrease in pain.

\section{Global assessment of efficacy of treatment}

Efficacy of treatment was assessed by the physician based on improvement in pain on visual analogue scale. It was assessed only on day 7 of treatment.

- Excellent: improvement in pain by $>90 \%$.

- Good: improvement in pain by $70-90 \%$.

- Average: improvement in pain by $50-70 \%$.

- Poor: improvement in pain by $<50 \%$.

\section{Safety assessment}

During the study, various adverse events reported by patients like drowsiness, nausea, vomiting, abdominal pain, diarrhoea, and dizziness or any other were recorded. 


\section{Statistical analysis}

The data collected were tabulated and analysed using descriptive statistical tools like mean and standard deviation. Comparison between the groups was done by student' ${ }^{\prime}$ ' test and within the group by ANOVA test. Chi square test was used for non-parametric data. $\mathrm{P}<0.05$ was considered as significant.

\section{RESULTS}

In this study, total 155 patients were enrolled which were randomly allocated into two groups; 78 patients belonged to Group A and 77 patients belonged to Group B.

These patients were followed up for 7 days. Both the groups were similar in demographic and baseline characteristics (Table 1).

\section{Efficacy assessment}

FFD: A significant effect of both tolperisone and thiocolchicoside was observed on finger to floor distance. The mean change in FFD from baseline was statistically significant on day 3 as well as on day 7 with both the drugs $(p<0.0001)$. The mean FFD decreased from baseline of $15.7 \pm 11.66 \mathrm{~cm}$ to $6.57 \pm 6 \mathrm{~cm}$ on day 7 in group A and from $17.19 \pm 14.53 \mathrm{~cm}$ to $8.55 \pm 8.32 \mathrm{~cm}$ on day 7 in group B. Percentage change in mean FFD from baseline was $32.99 \%$ and $58.15 \%$ respectively on day 3 and day 7 of treatment in Group A and $31.41 \%$ and $50.26 \%$ respectively on day 3 and day 7 of treatment in Group B.

Though clinical improvement was more in Group A on day 3 as well as on day 7, there was no statistically significant difference in response to treatment between the two groups on day $3(\mathrm{p}=0.449)$ and on day $7(\mathrm{p}=0.092)$ (Table 2).

Table 1: Baseline characteristics in study groups.

\begin{tabular}{|c|c|c|c|c|}
\hline \multicolumn{2}{|c|}{ Parameters } & $\begin{array}{l}\text { Group A } \\
\text { tolperisone + etodolac }\end{array}$ & $\begin{array}{l}\text { Group B } \\
\text { thiocolchicoside + etodolac }\end{array}$ & P value \\
\hline \multicolumn{2}{|c|}{ Age (years) } & $33.97 \pm 8.55$ & $35.84 \pm 9.41$ & 0.197 \\
\hline \multirow{2}{*}{ Gender } & Males & 33 & 37 & \multirow{2}{*}{0.379} \\
\hline & Females & 45 & 40 & \\
\hline \multirow{2}{*}{\multicolumn{2}{|c|}{$\begin{array}{l}\text { Finger to floor distance }(\mathrm{cm}) \\
\text { VAS score of pain }\end{array}$}} & $15.7 \pm 11.66$ & $17.19 \pm 14.53$ & 0.482 \\
\hline & & $4.72 \pm 1.6$ & $4.86 \pm 1.97$ & 0.630 \\
\hline
\end{tabular}

Table 2: Response to treatment with tolperisone and thiocolchicoside in combination with etodolac on day 3 and 7 on finger to floor distance and VAS.

\begin{tabular}{|lllll|}
\hline \multirow{2}{*}{ Parameters } & \multicolumn{1}{c}{$\begin{array}{l}\text { Group A } \\
\text { Tolperisone }+ \text { etodolac } \\
(\text { mean } \pm \text { SD) }\end{array}$} & $\begin{array}{l}\text { Group B } \\
\text { Thiocolchicoside + etodolac } \\
(\text { mean } \pm \text { SD) }\end{array}$ & P value \\
\hline $\begin{array}{l}\text { Finger to floor } \\
\text { distance }(\mathbf{c m})\end{array}$ & Day 0 & $15.7 \pm 11.66$ & $17.19 \pm 14.53$ & 0.482 \\
\cline { 2 - 5 } & Day 3 & $10.52 \pm 9.66$ & $11.79 \pm 11.2$ & 0.449 \\
\hline \multirow{2}{*}{$\begin{array}{l}\text { VAS score of } \\
\text { pain }\end{array}$} & Day $~$ & $6.57 \pm 6$ & $8.55 \pm 8.32$ & 0.092 \\
\cline { 2 - 5 } & Day 3 & $4.72 \pm 1.6$ & $4.86 \pm 1.97$ & 0.630 \\
\cline { 2 - 5 } & Day 7 & $2.97 \pm 2.17$ & $3.17 \pm 2.38$ & 0.595 \\
\hline
\end{tabular}

VAS: There was significant reduction in pain score in both the groups $(\mathrm{p}<0.0001)$. In Group A, mean VAS score was decreased from baseline value of $4.72( \pm 1.6)$ to 1.86 $( \pm 1.82)$ on day 7 , while in group B the VAS score was decreased from $4.86( \pm 1.97)$ to $2.27( \pm 2.18)$ on day 7 . (Table 2)

\section{Global assessment of efficacy by physician}

As per the assessment by physician, tolperisone produced good to excellent efficacy in $46.14 \%$ patients while, thiocolchicoside produced good to excellent efficacy in $40.25 \%$ patients (Table 3 ).

\section{Safety evaluation}

Only 7 patients out of 78 developed side effects in tolperisone group while 8 patients out of 77 developed side effects in thiocolchicoside group.

Most common adverse events reported in Group A were nausea $(2.56 \%)$ and abdominal pain $(2.56 \%)$, with one patient each of drowsiness, vomiting, and dizziness (1.28\% each). In Group B, most common adverse events reported were nausea $(3.89 \%)$, vomiting $(2.60 \%)$, and drowsiness $(2.60 \%)$, with one patient each of abdominal pain, diarrhoea and dizziness (1.30\% each). All the events were of mild intensity and did not result in discontinuation of treatment. 
Table 3: Table representing global assessment of efficacy by physician.

\begin{tabular}{|c|c|c|c|c|}
\hline \multirow{3}{*}{$\begin{array}{l}\text { Global assessment of } \\
\text { efficacy }\end{array}$} & \multicolumn{2}{|c|}{ No. of patients } & \multirow{3}{*}{$\begin{array}{l}\text { Chi square } \\
\text { value }\end{array}$} & \multirow{3}{*}{$P$ value } \\
\hline & Group A & Group B & & \\
\hline & $\mathbf{N}(\%)$ & $\mathbf{N}(\%)$ & & \\
\hline Excellent & $29(37.17)$ & $27(35.06)$ & \multirow{4}{*}{4.57} & \multirow{4}{*}{0.206} \\
\hline Good & $7(8.97)$ & $4(5.19)$ & & \\
\hline Average & $21(26.92)$ & $14(18.18)$ & & \\
\hline Poor & $21(26.92)$ & $32(41.55)$ & & \\
\hline
\end{tabular}

Table 4: Adverse drug reactions.

\begin{tabular}{|lll|}
\hline \multirow{2}{*}{ Side effects } & No. of patients & Group B \\
& Group A & N (\%) \\
\hline N (\%) & $3(3.89)$ \\
\hline Nausea & $2(2.56)$ & $2(2.60)$ \\
\hline Vomiting & $1(1.28)$ & $1(1.30)$ \\
\hline Diarrhoea & - & $1(1.30)$ \\
\hline Abdominal pain & $2(2.56)$ & $2(2.60)$ \\
\hline Drowsiness & $1(1.28)$ & $1(1.30)$ \\
\hline Dizziness & $1(1.28)$ & $10(12.99)$ \\
\hline Total & $7(8.96)$ & \\
\hline
\end{tabular}

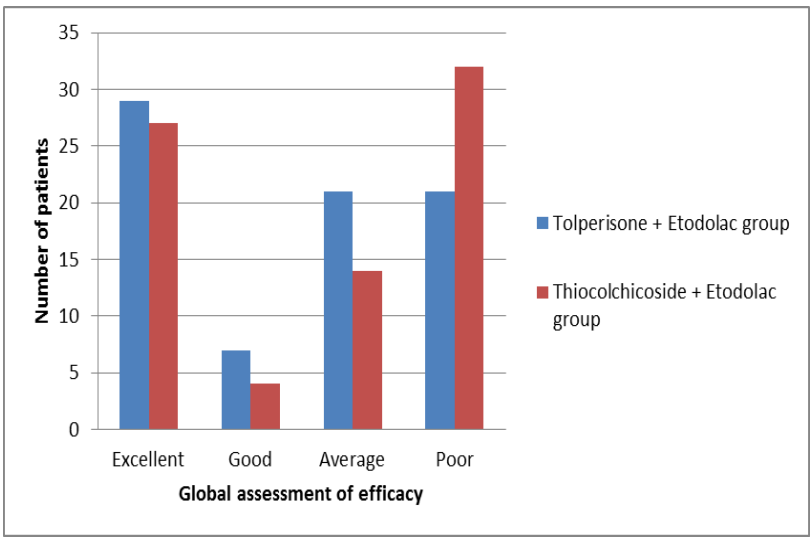

Figure 1: Global assessment of efficacy.

\section{DISCUSSION}

Incidence of low back pain is increasing in developing countries due to modernization, lack of exercise and postural problems. Patients prefer the drugs which decrease the pain as well as muscle spasm so that they can return back to normal activities as early as possible without any compromise in the quality of life.

In this study, both tolperisone and thiocolchicoside in combination with etodolac significantly decreased muscle spasm, pain and increased the mobility of spine.

In this study, mean age of occurrence of LBP was $33.97 \pm 8.55$ years in tolperisone and etodolac group while $35.84 \pm 9.41$ years in thiocolchicoside and etodolac group, the difference being statistically not significant $(\mathrm{p}=0.197)$.
Number of females $(54.84 \%)$ was more than the number of males $(45.16 \%)$ in this study which was consistent with the results of previous studies (Bhattacharjya et al, Ketenci et al, Soonawalla et al). ${ }^{5,6,8}$

Tolperisone decreased FFD from baseline value of 15.7 $\mathrm{cm}$ to $6.57 \mathrm{~cm}$ and with thiocolchicoside FFD value was decreased from 17.19 to $8.55 \mathrm{~cm}$ on day $7(\mathrm{p}<0.0001)$. Percentage change in mean FFD was $58.15 \%$ and $50.46 \%$ respectively in 2 groups. The difference was not statistically significant between the two groups. This decrease in muscle spasm in both groups was independent of its severity.

Mean VAS score was also reduced significantly from baseline value of 4.72 to 2.97 on day 3 and 1.86 on day 7 in tolperisone group while in thiocolchicoside group VAS score decreased from 4.86 to 3.17 and 2.27 on day 3 and 7 respectively $(\mathrm{p}<0.0001)$.

The results of this study correlate with the results of clinical trial by Rao et al, where tolperisone was shown to be an effective skeletal muscle relaxant agent with efficacy similar to thiocolchicoside. ${ }^{4}$ Several other studies like Prabhoo et al, Pratzel et al, Bhattacharjya et al, Maaz et al, Ambrish et al, also demonstrated tolperisone to have a significant effect in reducing pain intensity as well as muscle spasm. ${ }^{6,7,9-11}$

Thiocolchicoside acts by activating GABA-ergic inhibitory pathways and also has glycinergic action. It acts as centrally acting muscle relaxant. Its efficacy in improving the skeletal muscle spasm and pain has been demonstrated in various studies (Soonawalla et al, Tuzun et al, Ketenci et al, Saravanabhavan et al) where it has 
shown to decrease the finger to floor distance and also improve pain. ${ }^{5,8,12,13}$

Thus, the spasmolytic and pain reducing properties shown by thiocolchicoside in our study correlates with these studies.

Tolperisone is a centrally acting skeletal muscle relaxant which has multiple mechanisms of action. It acts at the level of spinal cord and exerts its spinal reflex inhibitory action by blocking voltage gated sodium and calcium channels, thus inhibiting the presynaptic release of neurotransmitter (glutamate) from primary afferent nerve endings. It blocks mono- and polysynaptic reflexes at the spinal level in a dose-dependent manner. It increases blood supply to skeletal muscles as muscle contracture compresses the small blood vessels and induces ischemia leading to release of pain stimulating compounds. ${ }^{14}$

In this study, side effects produced were not serious and none of them resulted in discontinuation of therapy. Both the drugs were well tolerated. Tolperisone + etodolac group had a higher incidence of side effects like drowsiness $(11.53 \%)$, abdominal pain $(11.53 \%)$, nausea (10.25\%), vomiting (5.1\%), diarrhoea (3.84\%) as compared to thiocolchicoside + etodolac group. Centrally acting muscle relaxants are associated with central nervous system side effects like drowsiness, dizziness which is common with all available centrally acting muscle relaxants. In this study, tolperisone group produced drowsiness in $11.53 \%$ patients as compared to $3.9 \%$ patients in thiocolchicoside group. This effect is not correlated with other studies which have shown tolperisone to be devoid of sedative side effect (Dulin et al, Rao et al, Quasthoff et al)., ${ }^{4,16}$

\section{CONCLUSION}

It is evident from this study that both the drugs showed significant clinical improvement in pain as well as muscle spasm independent of the severity of the spasm. But side effect profile of tolperisone and etodolac was less favourable as compared to thiocolchicoside and etodolac group in this study as numbers of adverse events reported in the tolperisone and etodolac group were higher.

Thus in the light of this study, we recommend thiocolchicoside over tolperisone for the management of patients presenting with acute low back pain with muscle spasm.

The limitations of this study were the small sample size and short follow-up. Comparative studies between the two drugs with a large number of patients and longer followup is required to assess their effectiveness and safety profile.

\section{Funding: No funding sources}

Conflict of interest: None declared

Ethical approval: The study was approved by the Institutional Ethics Committee

\section{REFERENCES}

1. Andersson GB. Epidemiology of low back pain. Acta Orthop Scand Suppl. 1998;281:28-31.

2. Cohen SP, Argoff CE, Carragee EJ. Management of low back pain. BMJ. 2008;337:a2718.

3. Everett C Hills. Mechanical low back pain. Medscape 2012. Available at: http://emedicine.medscape. com/article/310353-overview. Accessed on 11 October 2012.

4. Rao R, Panghate A, Chandanwale A, Sardar I, Ghosh M, Roy M, et al. Clinical comparative study: efficacy and tolerability of tolperisone and thiocolchicoside in acute low back pain and spinal muscle spasticity. Asian Spine J. 2012;6(2):115-22.

5. Soonawalla DF, Joshi N. Efficacy of thiocolchicoside in Indian patients suffering from low back pain associated with muscle spasm. J Indian Med Assoc. 2008;106(5):331-5.

6. Bhattacharjya B, Naser SM, Biswas A, Kamal F, Banerjee K. Effectiveness of Tolperisone Hydrochloride with Aceclofenac as combined therapy in acute low back pain. IJPMR. 2012;23(2):74-8.

7. Prabhoo R, Keny S, Prabhoo T, Singh A, Rana R. A Phase IV observational multi-centre, open-label study on efficacy and safety of tolperisone $150 \mathrm{mg}$ in patients with painful muscle spasm associated with degenerative or inflammatory diseases of the musculoskeletal System. J Assoc Physicians India. 2011;59:33-7.

8. Ketenci A, Ozcon E, Karamursel S. Assessment of efficacy and psychomotor performances of Thiocolchicoside and Tizanidine in patients with acute low back pain. Int J Clin Pract. 2005;59(7):76470.

9. Pratzel HG, Alken RG, Ramm S. Efficacy and tolerance of repeated oral doses of tolperisone hydrochloride in the treatment of painful reflex muscle spasm: results of a prospective placebocontrolled double-blind trial. Pain. 1996;67(2-3):41725.

10. Maaz SH, Khandelwal PN, Baig M, Doifode SM, Ghotkar UM. Evaluation of efficacy and tolerability of eperisone and thiocolchicoside in treatment of low back pain associated with muscle spasm: An open label, prospective, randomized controlled trial. Int $\mathbf{J}$ Basic Clin Pharmacol. 2016;5(6):2669-74.

11. Ambrish S, Nagesh Raju G, Dharmaraj B, Nagendra Gowda M R. A Comparative study of efficacy of Thiocolchicoside with Diclofenac vs Eperisone with Diclofenac in patients with back pain. Int $\mathrm{J}$ surg Orthop. 2017;3(1):1-5.

12. Tuzun F, Unalan H, Oner N, Ozgüzel H, Kirazli Y, Icagasioglu A et al. Multicenter, randomized, doubleblinded, placebo-controlled trial of thiocolchicoside in acute low back pain. Joint Bone Spine. 2003;70(5):356-61.

13. Saravanabhavan S, Kuchake V, Al-Saikhan FI. Comparative efficacy and safety of Methocarbamol 
and Thiocolchicoside in acute low back pain. World $\mathrm{J}$ Pharm Pharma Sci. 2014;3(4):276-86.

14. Vora A. Tolperisone. J Assoc Physicians India. 2010;58:127-8.

15. Dulin J, Kovacs L, Ramm S, Horvath F, Ebeling L, Kohnen R. Evaluation of sedative effects of single and repeated doses of $50 \mathrm{mg}$ and $150 \mathrm{mg}$ Tolperisone Hydrochloride. Results of a Prospective, Randomized, Double-blind, Placebo-controlled trial. Pharmacopsychiatry. 1998;31(4):137-42.

16. Quasthoff S, Mockel C, Zieglgansberger W, Schreibmayer W. Tolperisone: a typical representative of a class of centrally acting muscle relaxants with less sedative side effects. CNS Neurosci Ther. 2008;14(2):107-19.

Cite this article as: Garg T, Yadav VK. A comparative study on safety and efficacy of tolperisone with etodolac and thiocolchicoside with etodolac in patients of acute low back pain with musculoskeletal spasm. Int J Basic Clin Pharmacol 2019;8:2459-64. 